\title{
Macroeconomic dynamics in a model of goods, labor, and credit market frictions
}

\author{
Nicolas Petrosky-Nadeau ${ }^{\mathrm{a}, \mathrm{b}}$, Etienne Wasmer ${ }^{\mathrm{c}, \mathrm{n}}$ \\ ${ }^{a}$ Federal Reserve Bank of San Francisco, 101 Market St., San Francisco, CA 94105, United States \\ b Tepper School of Business, Carnegie Mellon University, 5000 Forbes Avenue, Pittsburgh, PA 15213, United States \\ ${ }^{c}$ Sciences Po, Paris, Departement d'Economie, 28 Rue des Saint-Pères, 75007 Paris, France
}

\begin{abstract}
A B S T R A C T
Goods market frictions drastically change the dynamics of the labor market, both in terms of persistence and volatility. In a model with three imperfect markets - goods, labor, and credit - we find that credit and goods market imperfections are substitutable in raising volatility. Goods market frictions are unique in generating persistence. Two key mechan-isms in the goods market generate large hump-shaped responses to productivity shocks: countercyclical goods market tightness and prices alter future profit flows and raise persistence; procyclical search effort of consumers and firms raises amplification. Goods market frictions are thus key in understanding labor market dynamics.
\end{abstract}

\author{
Keywords: \\ Goods market search \\ Labor market dynamics \\ Propagation \\ Credit market frictions
}

\section{Introduction}

The propagation of productivity shocks has been at the core of the real business cycle (RBC) research agenda since its inception. The need for large innovations to obtain realistic business cycle fluctuations, and the lack of any quantitatively significant endogenous persistence mechanism in the RBC model, has been emphasized in, respectively, King and Rebelo (1999) and Cogley and Nason (1995). The subsequent literature has focused on finding mechanisms that endogenously generate large and persistent responses to shocks.

The same issues and controversies arise when studying the cyclical dynamics of aggregate labor markets in the Mortensen-Pissarides search-and-matching model. The central variable in search models of the labor market, the ratio of job vacancies to unemployment, is very volatile in the data, and its response to a productivity shock peaks several quarters after the innovation. In a standard labor search model, however, this ratio reacts very little to productivity shocks and the peak response of the $v-u$ ratio is contemporaneous to the innovation. In response, a large body of research has developed amplifying mechanisms with some works focusing on the role of frictions in labor and credit markets. ${ }^{1}$ However, few of these papers have addressed the issue of persistence. Our approach - which integrates and evaluates frictions in three markets, labor, credit, and goods - aims precisely to address this issue. The paper studies how these frictions interact to

\footnotetext{
* Corresponding author.

E-mail addresses: npn@cmu.edu (N. Petrosky-Nadeau), etienne.wasmer@sciences-po.fr (E. Wasmer).

${ }^{1}$ For research on focusing on amplification in the labor market, see Shimer (2005) and Hall (2005), while Fujita and Ramey (2007) raise the issue of persistence. For financial frictions, we refer to the large literature on financial multipliers surveyed in Gertler and Kiyotaki (2013). Section 5 offers a detailed discussion of the relevant literature.
} 
propagate exogenous shocks to productivity and decompose the role of each friction in generating amplification and persistence.

The paper develops a model with three imperfect markets - goods, labor, and credit - building on the general equilibrium model with credit and labor market frictions in Wasmer and Weil (2004) and Petrosky-Nadeau and Wasmer (2013), and identify which market frictions are needed to match the cyclical properties of labor market variables in the data. The modeling strategy represents each friction as a process matching two sides of the three markets, respectively, jobs, lending relationships, and goods. Although this assumption is now well accepted in the labor and financial markets (e.g., Duffie et al., 2005), it is quite novel in modeling goods market frictions, and indeed, it is only recently that this approach has proven useful in the macro-labor literature. ${ }^{2}$ The goods market was, however, the prototypal market in the early search literature (e.g., Diamond, 1982). Moreover, Diamond's (2011) Nobel lecture emphasizes developments in modeling search frictions in the goods market, and in particular their implications for unemployment.

The bilateral matching process leads to several appealing properties which are absent in a frictionless view of markets. As put forward in the macro-search literature (Mortensen and Pissarides, 1999; Rogerson and Shimer, 2011), the relative measure of supply and demand in each market captures the degree of market tightness: the familiar vacancy-unemployment ratio in the labor market, the ratio of prospecting consumers and products in the goods market, and the ratio of investment projects to creditors in the credit market. Further, it introduces endogenous mark ups, turnover in each market, and search effort. In addition, a matching model of the goods market has interesting implications. In the goods market, for instance, consumer search effort is procyclical in the model, searching more when they have higher income and when more firms supply goods, as is the case in the data. ${ }^{3}$ As Table 1 from the American Time Use Survey over the 2003-2011 period reports, the average time spent in a day on shopping activities declined during the last recession, with the exception of grocery shopping which remained stable. ${ }^{4}$

Our main insight is a surprising one: goods market frictions drastically change the qualitative and quantitative dynamics of the labor market. They amplify shocks just as credit market frictions do. They are unique, however, in being able to generate endogenous persistence and are thus better at bridging the gap with the data in terms of both persistence and volatility. The principal measure of persistence, the impulse response of labor market tightness to a productivity shock as identified in Fujita and Ramey (2007), peaks five quarters after this innovation. The model matches the amplitude and the shape of this hump-shaped response in the data. In previous work (Petrosky-Nadeau and Wasmer, 2013) in which goods market frictions were absent, and in line with a vast literature on financial market imperfections, it was only possible to significantly raise volatility by the presence of a financial multiplier arising from search frictions in the credit market. It was not able to address the challenge of persistence.

The dynamics in the goods market, and their effects on the incentives to hire workers, explain the persistent, hump shaped response of the $v-u$ ratio to a productivity shock. During the first stages of an economic expansion, more firms enter the goods market relative to the change in the effective demand from consumers. This higher competition between firms makes it more difficult for a given product to find a consumer and be sold. Prices, which are bargained, thus decline. This moderates the incentives to create a vacancy at the beginning of an expansion. As consumers see rising incomes and falling prices, they raise their search effort in the goods market to reach their desired consumption level. This, along with a slowdown in the entry of new products, leads to a further easing of the matching rate in the goods markets from the perspective of the firms in the periods after the technology shock. As such, firms are more likely to find a consumer, and sell at a higher price. The incentives to recruit workers increase even as productivity is returning to trend. These mechanisms in the goods market combine to generate both amplification and persistence in the labor market. Propagation arises from the fact that the economic value of hiring a worker is tied to the dynamics of prices and congestion in the goods market. These mechanisms are absent from environments using the standard labor search model. The right mix in the model of amplification and persistence depends on the combination of intensive and extensive search margins in the goods market. Intensive search margins (consumer's effort or advertisement by firms) are by definition less persistent than extensive search margins (the number of firms willing to sell, or number of prospecting consumers and their disposable income).

These properties of goods market frictions are robust to several alternative modeling strategies of the goods market. In particular, the results are robust to introducing endogenous search effort on both sides of the goods market, consumers and firms, separately and simultaneously, as well as to constant search effort. Furthermore, this additional amplification and persistence does not hinge on a particular wage determination schedule, and in particular does not arise from wage rigidity. ${ }^{5}$

\footnotetext{
${ }^{2}$ Recent papers include Bai et al. (2011), who model frictions in the goods market with a matching process between buyers and sellers, den Haan (2013), who models the friction on the seller's side of the goods market with a focus on the dynamics of inventories, and Gourio and Rudanko (2014) and Michaillat and Saez (2014). This research is discussed below and in Section 5.

${ }^{3}$ This observation is true in the aggregate (see Table 1), even if there may also exist incentives for consumers to search more for lower price in recessions - a mechanism absent from our model with no price dispersion across identical goods. See Shi (2011) as well as the early contribution in Shi (1998) discussed in Section 5 for the cyclical implications of search in the goods market. In a more recent note, Petrosky-Nadeau et al. (2014) show, based on the American Time Use Survey, that average time spent searching declined in the aggregate over the period 2008-2010 compared to 2005-2007, and the decline was largest for the unemployed who went from spending more to less time searching for goods than the employed. Cross-state regressions point towards a pro-cyclicality of consumer search in the goods market.

${ }^{4}$ In our model, essential goods such as food and utility will be frictionless goods and reflect this cyclical pattern. See Appendix section 1 for a description of the series.

${ }^{5}$ This is shown in a variety of ways. First, by implementing a reduced-form wage rule, proposed by Blanchard and Galí (2010), in which the wage elasticity can be controlled directly. Second, by allowing for Nash bargained wages.
} 
Table 1

American Time Use Survey.

\begin{tabular}{|c|c|c|c|}
\hline \multirow[t]{2}{*}{ Year } & \multicolumn{3}{|c|}{ Hours per day spent purchasing } \\
\hline & Goods and services & Of which consumer goods & Of which grocery shopping \\
\hline 2003 & 0.81 & 0.40 & 0.11 \\
\hline 2004 & 0.83 & 0.41 & 0.10 \\
\hline 2005 & 0.80 & 0.41 & 0.11 \\
\hline 2006 & 0.81 & 0.40 & 0.10 \\
\hline 2007 & 0.78 & 0.39 & 0.10 \\
\hline 2008 & 0.77 & 0.38 & 0.10 \\
\hline 2009 & 0.76 & 0.38 & 0.11 \\
\hline 2010 & 0.75 & 0.37 & 0.10 \\
\hline 2011 & 0.72 & 0.37 & 0.11 \\
\hline
\end{tabular}

Source: http://www.bls.gov/tus/, Civilian Population, Tables 1 and A1.

The model focuses on frictions in the goods market and one type of shock, productivity innovations. As such it leaves out other dimensions of the business cycle. For instance, the model does not speak to debt and equity dynamics in the data, features studied in Christiano et al. (2014) and Negro et al. (2011). Jermann and Quadrini (2012) use a parsimonious twoshock model - one to productivity and one to the enforcement parameter of a collateral constraint on loans - and replicate key statistics such as a procyclical equity payout and countercylical debt payout.

This paper is organized as follows. Section 2 develops the model. Section 3 calibrates the model to monthly U.S. data. Section 4 investigates the sources of propagation in detail. Section 5 reviews the literature and connects our model to the empirical evidence on goods market frictions. Section 6 concludes.

\section{An economy with goods, labor, and credit market frictions}

We consider the case of a firm evaluating marginal investment projects. These projects first need to obtain financing in the credit market. A financed project is then managed to maximize the value to the firm and the creditor, and needs to hire a worker to produce a good. Thus far the structure follows Wasmer and Weil (2004) and Petrosky-Nadeau and Wasmer (2013). However, the good cannot be sold until a consumer has been found. Once a match in the goods market is formed, consumers and producers bargain over the price. ${ }^{6}$ The creditor has a monopoly over the ability to allocate resources from one period to the next. There is no money in this economy in contrast with Berentsen et al. (2011) who study jointly a search-money framework with labor-market frictions and a focus on interest rates' impact on unemployment. In particular, it is assumed that consumers do not have the ability to transfer wealth from one period to the next. However, this assumption is not binding as, with search frictions in the goods market, savings can be shown to be a dominated strategy (see Appendix Section 6).

\subsection{Financing investment projects}

Time is discrete. In the first stage, an investment project is initially in need of a financial partner. This financing will cover the cost of recruiting a worker and the wage bill when the firm has not found a demand for its product. Prospecting on the credit market costs $\kappa_{I}$ units of effort per period of time. At time $t$, with probability $p_{t}$ the investment project finds a creditor, and with complementary probability it remains in this stage (denoted by $c$ for credit). A creditor pays a per-period screening $\operatorname{cost}, \kappa_{B}$, and meets a project with probability $\hat{p}_{t}$. The asset values of investment projects and creditors in this stage are denoted by $J_{c}$ and $B_{c}$, respectively. At meeting between creditor and project, both sides agree on the terms of a financial contract whereby the resulting costs of the project are financed by the creditor when the project's revenue is negative (in stages 2 and 3) and the project pays the banker when the revenue is positive (in stage 4). Going forward, we will be interested in the joint values to the creditor and the investment project, which is referred to as a firm. Let the value of a firm for each of the stages be denoted by $S_{j, t}=J_{j, t}+B_{j, t}$, with $j$ indicating the corresponding stage. ${ }^{7}$

Now matched with a creditor, the project enters the second stage where it prospects on the labor market to hire a worker. It must pay a per-period cost $\gamma$ to maintain an active job vacancy. With probability $q_{t}$, the firm is successful in hiring a worker, with complementary probability, it remains in this stage (denoted by $l$ for labor). Let $S_{l}$ denote the asset value in this stage. The firm offers a wage $w_{t}$ to the worker as long as the firm is active.

\footnotetext{
${ }^{6}$ Wasmer (2009) investigated a steady-state version of this economy with several differences, notably constant search effort and no dynamic implications. His focus was on the existence and uniqueness of the equilibrium. A result is that congestion in the goods market, the ratio of unmatched consumers to unmatched firms, is equal to one in the steady state. This property is proved, convenient for obtaining simple solutions, but does not hold out of the steady state.

${ }^{7}$ The Bellman equations for the entry of projects and creditors are relegate to Appendix Section 2 - that is, Eqs. (1)-(4) and (5)-(8). The Bellman equations of the value of a firm (matched creditor and project) in each stage can be obtained by summing the corresponding equations.
} 
In the third stage, now endowed with a worker, the firm could start producing $x_{t}$ units of output from this particular project and attempt to sell it on the goods market, but it has no customers. A consumer arrives with probability $\lambda_{t}$, and all production can be sold in the fourth stage because matched consumers will absorb the entire production. ${ }^{8}$ Assuming that production involves an operating cost $\Omega$ over and above the wage and that the good cannot be stored, the firm chooses not to produce in this stage (denoted by $g$ for goods market). The asset value of the firm in this stage is denoted $S_{g}$. Note that the creditor is still financing the firm by transferring the amount of resources necessary to pay the worker.

In the fourth and final stage, the firm is now matched with a consumer and its output $x_{t}$ is sold at price $\mathcal{P}_{t}$. We assume that $x_{t}$ is a random, stationary process. With revenue $\mathcal{P}_{t} x_{t}$, the firm pays the worker $w_{t}$, the operating cost $\Omega$, an amount $\rho_{t}$ to the creditor, and enjoys the difference. ${ }^{9}$ Denote this stage by $\pi$, standing for profit and use $S_{\pi}$ for its associated asset value. In addition, the consumer may stop consuming the particular good produced by this project with probability $\tau$, in which case the project returns to the previous stage $g$ to search for another consumer. It is important to note that the termination of this relation in the goods market does not entail the exit of the product. Rather, the product returns to the previous stage searching for a new costumer in the goods market.

There are two additional types of separation. First, workers may choose to separate from the firm, which occurs each period with probability $s^{L}$. Second, the match between the investment project and its creditor may dissolve, leading to bankruptcy. These two separation events allow us to distinguish a small bankruptcy rate in the business sector, typically around $s^{c}=1 \%$ quarterly, from the larger turnover rate of workers, here $s=s^{c}+\left(1-s^{c}\right) s^{L}{ }^{10}$

Finally, as in Pissarides (2000), all profit opportunities are exhausted by new entrants such that the value of the entry stages are always driven to zero. In the case of the credit market, this implies that $J_{c, t}=B_{c, t} \equiv 0$ at all times, which is also the continuation value following the credit destruction shock $s^{c}$ that can occur at the end of every stage. This results in the following Bellman equations:

$$
\begin{aligned}
& S_{c, t}=0 \Leftrightarrow \frac{\kappa_{B}}{\hat{p}_{t}}+\frac{\kappa_{I}}{p_{t}}=S_{l, t} \\
& S_{l, t}=-\gamma+\frac{1-s^{c}}{1+r} \mathbb{E}_{t}\left[q_{t} S_{g, t+1}+\left(1-q_{t}\right) S_{l, t+1}\right] \\
& S_{g, t}=-w_{t}+\frac{1-s^{c}}{1+r} \mathbb{E}_{t}\left[\left(1-s^{L}\right)\left[\lambda_{t} S_{\pi, t+1}+\left(1-\lambda_{t}\right) S_{g, t+1}\right]+s^{L} S_{l, t+1}\right] \\
& S_{\pi, t}=\mathcal{P}_{t} x_{t}-w_{t}-\Omega+\frac{1-s^{c}}{1+r} \mathbb{E}_{t}\left[\left(1-s^{L}\right)\left[(1-\tau) S_{\pi, t+1}+\tau S_{g, t+1}\right]+s^{L} S_{l, t+1}\right]
\end{aligned}
$$

Eq. (1) states that the value of a firm in the hiring stage is equal to the sum of capitalized search costs paid by each side in the previous credit market stage. This is driven to zero in the absence of credit market frictions. The formulation the labor market stage in Eq. (2) describes the value of a job vacancy as a flow cost $\gamma$ and an expected gain from hiring a worker, valued at $S_{g .}\left(1-S^{c}\right)$ is the survival probability of the credit relationship with the complementary probability that the match's value is zero (dissolution of the match). The value of $S_{g}$ in Eq. (3) takes into account the labor cost $w_{t}$, and, conditional on no bankruptcy $\left(1-s_{c}\right)$, the firm may or may not become profitable in the next period. This depends on meeting customers with probability $\lambda_{t}$, and whether the worker remains with the firm with probability $\left(1-s^{L}\right)$. If the worker leaves, the firm returns to the earlier stage $l$. The presence of a frictional goods market fundamentally alters the dynamics of $S_{\mathrm{g}}$ compared to the standard framework (e.g., Pissarides, 2000; Shimer, 2005) through the dynamics of the goods market meeting rate, $\lambda_{t}$, and the price, $\mathcal{P}_{t}$. Finally, in stage $\pi$, Eq. (4) shows that the match produces revenue $\mathcal{P}_{t} x_{t}$, pays a wage and other production costs, and may return to earlier stages depending on the occurrence of consumer change of taste, labor turnover, or bankruptcy. The repayment $\rho_{t}$ does not appear in the last equation, as it is merely a transfer between the project and the creditor.

\subsection{Search and matching in the goods markets}

\subsubsection{Matching in the goods market}

Consumers may spend a disposable income $Y^{d}$, defined below, on either an essential good (serving as a numeraire), $c_{0}$, or a preferred manufactured good, $c_{1}$. Consuming the latter first requires searching in the goods market. When a consumer is matched with a manufacturing firm, it purchases the production, $x_{t}$, at a unit price $\mathcal{P}_{t}$. The remaining income is spent on the essential good, which is supplied as a transfer of resources across individuals. ${ }^{11}$

\footnotetext{
${ }^{8}$ An alternative interpretation of $x_{t}$ is a quality shock affecting consumers' utility when the good produced is indivisible.

${ }^{9}$ Other papers in the literature consider sources other than productivity shocks as the driving force of fluctuations. See Bai et al. (2011) for demand shocks and Altig et al. (2011) for investment-specific shocks. Our analysis is restricted to the more standard productivity shock as new frictions are introduced into the model. The model is evaluated accordingly.

${ }^{10}$ Carlstrom and Fuerst (1997) provide a discussion of bankruptcy statistics.

${ }^{11}$ To avoid any further complication, the numeraire is assumed to be produced by a technology without labor. The extension of our framework along the lines of Berentsen et al. (2011) with money-search would permit richer interpretations.
} 
At any point in time in this economy there are matched and unmatched consumers. Normalizing the mass of consumers to 1 , these shares are denoted by $\mathcal{C}_{1, t}$ and $\mathcal{C}_{0, t}$, respectively. In equilibrium, these will be the fractions of disposable household income allocated to either category of goods. Unmatched consumers $\mathcal{C}_{0, t}$, exert an average search effort, $\bar{e}_{c, t}$, to find unmatched goods, $\mathcal{N}_{g, t}$, through a process summarized by a constant returns-to-scale function, $M_{G}\left(\bar{e}_{c, t} \mathcal{C}_{0, t}, \mathcal{N}_{g, t}\right)$. Thus, $\bar{e}_{c, t} \mathcal{C}_{0, t}$ can be thought of as the effective demand for new goods. Following Pissarides (2000), the aggregate meeting rates for consumers and firms are

$$
\begin{aligned}
& \lambda_{t}=\frac{M_{G}\left(\bar{e}_{c, t} \mathcal{C}_{0, t}, \mathcal{N}_{g, t}\right)}{\mathcal{N}_{g, t}}=\lambda\left(\xi_{t}, \bar{e}_{c, t}\right) \quad \text { with } \lambda^{\prime}\left(\xi_{t}\right)>0 \\
& \tilde{\lambda}_{t}=\frac{M_{G}\left(\bar{e}_{c, t} \mathcal{C}_{0, t}, \mathcal{N}_{g, t}\right)}{\mathcal{C}_{0, t}}=\tilde{\lambda}\left(\xi_{t}, \bar{e}_{c, t}\right) \quad \text { with } \tilde{\lambda}^{\prime}\left(\xi_{t}\right)<0,
\end{aligned}
$$

where $\xi_{t}=\mathcal{C}_{0, t} / \mathcal{N}_{g, t}$ is tightness in the goods market (from the consumers' point of view); $\tilde{\lambda}_{t}$, the probability that an unmatched consumer finds a suitable firm from which to buy goods, is decreasing in goods-market tightness. Conversely, the greater $\xi_{t}$, the greater the demand from consumers relative to goods awaiting consumers, and the shorter the producer's search. This is precisely what creates the feedback from the goods to the labor market: the returns to hiring a worker are greater when it is easier to find customers.

\subsubsection{Disposable income}

Total net profits in this economy, $\Pi_{t}$, are the sum of profit flows to projects and creditors:

$$
\Pi_{t}=\left(\mathcal{P}_{t} x_{t}-\Omega\right) \mathcal{N}_{\pi, t}-w_{t} \mathcal{N}_{t}-\gamma \mathcal{N}_{l, t}-\kappa_{B} \mathcal{B}_{c, t},
$$

where $\mathcal{N}_{t}=\mathcal{N}_{\pi, t}+\mathcal{N}_{g, t}$ is the sum of the number of firms matched with a consumer, $\mathcal{N}_{\pi, t}$, and of the number of firms in stage $g, \mathcal{N}_{g, t}$, (that is, matched with a creditor and a worker but not with a consumer). The number of firms prospecting for workers in stage $l$, the labor market, is $\mathcal{N}_{l, t}$, and the number of creditors screening projects in stage $c$ is $\mathcal{B}_{c, t}$. In the equation above, the first term is revenue generated by firms in stage 4 , net of operating costs. The second term represents wage payments in the economy. The remaining terms represent the creditor's outlays during the first stages due to search costs in labor and credit markets.

The profits net of search costs and other resources are pooled and distributed as lump sums to workers as in Merz (1995) and Andolfatto (1996). Each worker, unemployed and employed, therefore receives an average disposable income $\Pi_{t}+\mathcal{N}_{t} w_{t} \cdot{ }^{12}$

\subsubsection{Value functions for consumers}

Individuals want to consume manufactured goods but may not buy them before searching in the goods market. Let us denote by $D_{0, t}$ and $D_{1, t}$ the values for a consumer of being unmatched and matched, respectively. The generic utility of consuming both goods is denoted by $\mathcal{U}\left(c_{1}, c_{0}\right)$. Unmatched consumers search for a good at an effort cost $\sigma\left(e_{c, i}\right)$, with $\sigma^{\prime}\left(e_{c, i}\right)>0, \sigma^{\prime \prime}\left(e_{i}\right) \geq 0$, and $\sigma(0)=0$, with elasticity with respect to effort $\eta_{\sigma}>0$. They perceive their search effort as influencing their effective finding rate, $e_{c, i, t} \tilde{\lambda}_{t} / \bar{e}_{c, t}$, where $\bar{e}_{c, t}$ was defined above as aggregate consumer search effort. Consequently,

$$
\begin{aligned}
& \left.D_{0, t}=\mathcal{U}\left(0, c_{0, t}\right)-\sigma\left(e_{c, i, t}\right)+\frac{1}{1+r} \mathbb{E}_{t}\left[\frac{e_{c, i, t} \tilde{\lambda}_{t}}{\bar{e}_{c, t}} D_{1, t+1}+1-\frac{e_{c, i, t} \tilde{\lambda}_{t}}{\bar{e}_{c, t}}\right) D_{0, t+1}\right] \\
& D_{1, t}=\mathcal{U}\left(c_{1, t}, c_{0, t}\right)+\frac{\left(1-s^{c}\right)\left(1-s^{L}\right)}{1+r} \mathbb{E}_{t}\left[\tau D_{0, t+1}+(1-\tau) D_{1, t+1}\right]+\frac{s^{c}+\left(1-s^{c}\right) s^{L}}{1+r} \mathbb{E}_{t} D_{0, t+1}
\end{aligned}
$$

Assuming the manufactured good has greater marginal utility, matched consumers will always absorb $x_{t}$ units of good 1 at the expense $\mathcal{P}_{t} x_{t}$, and then expend what is left, $Y_{t}^{d}-\mathcal{P}_{t} x_{t}$, on $c_{0, t}$. In other words, the utility in the first equation (unmatched consumer) is $\mathcal{U}\left(0, Y_{t}^{d}\right)$, and the utility in the second equation (matched consumer) will be $\mathcal{U}\left(x_{t}, Y_{t}^{d}-\mathcal{P}_{t} x_{t}\right)$. Finally, going forward, consumer utility is assumed to have the linear form:

$$
\mathcal{U}\left(c_{1, t}, c_{0, t}\right)=\Phi c_{1, t}+c_{0, t}
$$

with the assumption that $\Phi \geq 1$.

\subsubsection{Optimal search effort}

The optimal individual search effort is given by a condition equating the marginal cost of effort to the discounted, expected benefit yielded by that marginal unit of effort:

$$
\bar{e}_{c, t} \sigma^{\prime}\left(e_{c, i, t}^{*}\right)=\frac{\tilde{\lambda}_{t}}{1+r} \mathbb{E}_{t}\left[\left(D_{1, t+1}-D_{0, t+1}\right)\right]
$$

\footnotetext{
${ }^{12}$ An alternative timing, where the disposable income in $t$ would be generated through profits and sales from period $t-1$ would affect the dynamics and add a source of persistence, which is avoided here by our specification. The dynamic path obtained is thus not artificially slowed.
} 
Eq. (7) implies that consumer search effort is increasing in the expected capital gain from consuming the manufactured good, and it follows that all consumers exert the same effort: $e_{c, t}^{*}=\bar{e}_{c, t}$.

Combining the first-order condition above and the asset-value equations for consumers, yields ${ }^{13}$ :

$$
\bar{e}_{c, t} \sigma^{\prime}\left(\bar{e}_{c, t}\right)=\frac{\tilde{\lambda}_{t}}{1+r} \mathbb{E}_{t} \sum_{i=0} \psi^{i}\left[\left(\frac{\Phi}{\mathcal{P}_{t+1+i}}-1\right) Y_{t+1+i}^{d}+\left(1-\eta_{\sigma}\right) \sigma\left(\bar{e}_{c, t+1+i}\right)\right],
$$

where $\psi \equiv(1-\tau)\left(1-s^{L}\right)\left(1-s^{c}\right) /(1+r)$ is a discount factor. This expression reveals that the level of effort will depend on expected disposable income and the dynamics of the price $\mathcal{P}$. A drop in the price raises the incentive to exert search effort in the goods market, as does an expected increase in future income.

\subsubsection{Determining the dynamics of the goods surplus and price}

Consistent with the search literature, we postulate that the price $\mathcal{P}_{t}$ is bargained between a consumer and a firm. The total surplus to the consumption relationship is $G_{t}=\left(S_{\pi, t}-S_{g, t}\right)+\left(D_{1, t}-D_{0, t}\right)$. The good's price is determined as $\mathcal{P}_{t}=\operatorname{argmax}\left(S_{\pi, t}-S_{g, t}\right)^{1-\delta}\left(D_{1, t}-D_{0, t}\right)^{\delta}$, where $\delta \in(0,1)$ is the share of the goods surplus, $G_{t}$, going to the consumer. This results in the sharing rule:

$$
(1-\delta)\left(D_{1, t}-D_{0, t}\right)=\delta\left(S_{\pi, t}-S_{g, t}\right),
$$

from which the negotiated price rule is

$$
\mathcal{P}_{t} x_{t}=(1-\delta)\left[\Phi x_{t}+\left(1-\eta_{\sigma}\right) \sigma\left(\bar{e}_{c, t}\right)\right]+\delta \Omega+(1-\delta) \lambda_{t}\left(1-s^{L}\right) \frac{1-s^{c}}{1+r} \mathbb{E}_{t}\left[\delta G_{t+1}\right] .
$$

This rule emphasizes the forward-looking aspect of price determination: today's price is increasing in the expectation of tomorrow's surplus in the goods market. The latter effect on price depends on current goods market congestion through the meeting rate, $\lambda_{t}$, capturing the incidence of greater competition for consumers in goods markets on prices. Greater effective demand relative to the supply of unmatched goods $\mathcal{N}_{g}$, or more market tightness $\xi_{t}$, leads to a higher price. In addition, Eq. (10) states that the revenue accruing to the firm is increasing in the marginal utility, $\Phi$, from consuming good $c_{1}$. By assuming convex costs - that is, an elasticity $\eta_{\sigma}>1$ - the effect of consumer search effort is negative. This is a pure surplus effect: when effort increases, the consumer's surplus increases ceteris paribus because it negatively affects the value of consumption search, $D_{0, t}$. Now, as the consumption of good 1 is inelastic, an increase in the price reduces the consumption of $c_{0}$ one for one. Hence, for a given bargaining strength $\delta$, there must be a negative association between price and effort. Together with changes in goods market tightness this will generate a counter-cyclical price.

\subsection{Matching in other markets}

\subsubsection{Matching and the division of rents in the credit market}

The matching rates $p_{t}$ and $\widehat{p}_{t}$ are made mutually consistent by the existence of a matching function $M_{C}\left(\mathcal{B}_{c, t}, \mathcal{N}_{c, t}\right)$, where $\mathcal{B}_{c, t}$ and $\mathcal{N}_{c, t}$ are, respectively, the number of creditors and projects in stage $c$. This function is assumed to have constant returns-to-scale. Hence, denoting by $\phi_{t}$ the ratio $\mathcal{N}_{c, t} / \mathcal{B}_{c, t}$, which reflects tightness of the credit market from the project's point of view, the matching rates are

$$
\begin{aligned}
& p_{t}=\frac{M_{C}\left(\mathcal{B}_{c, t}, \mathcal{N}_{c, t}\right)}{\mathcal{N}}=p\left(\phi_{t}\right) \quad \text { with } p^{\prime}\left(\phi_{t}\right)<0 \\
& \hat{p}_{t}=\phi_{t} p\left(\phi_{t}\right) \quad \text { with } \widehat{p}^{\prime}\left(\phi_{t}\right)>0 .
\end{aligned}
$$

The rents from implementing a project, $S_{l, t}$, are divided by bargaining about $\rho$, upon meeting. Calling $\beta \in(0,1)$ the bargaining power of the creditor, the Nash bargaining condition:

$$
(1-\beta) B_{l, t}=\beta J_{l, t} \text {, }
$$

states that with $\beta=1$ the creditor receives all the surplus. Note that the rule for $\rho$ is determined at the time of the meeting but paid a few periods after the negotiation, when the firm becomes profitable. It is assumed there is no commitment problem, as in Wasmer and Weil (2004), so that any new realization of aggregate productivity will not undo the financial contract and there is no renegotiation.

Free entry of both creditors and projects to credit markets implies a constant credit market tightness over time, even out of the steady state (see Petrosky-Nadeau and Wasmer, 2013):

$$
\phi^{*}=\frac{\kappa_{B}}{\kappa_{I}} \frac{1-\beta}{\beta} \quad \forall t
$$

\footnotetext{
${ }^{13}$ The details of the derivation for this and subsequent equations are provided in Appendix Section 3.
} 
Going forward, all the information pertaining to the credit market is contained in the total transaction costs paid by both firms and creditors in stage $c$, a constant of parameters:

$$
K \equiv \frac{\kappa_{B}}{\phi^{*} p\left(\phi^{*}\right)}+\frac{\kappa_{I}}{p\left(\phi^{*}\right)}
$$

\subsubsection{Matching in the labor market and wage determination}

Matching in the labor market is governed by a function $M_{L}\left(\mathcal{N}_{l, t}, u_{t}\right)$, where $u_{t}$ is the rate of unemployment and the total number of unemployed workers since the labor force is normalized to $1 . \mathcal{N}_{l, t}$, already defined as the number of firms in stage $l$, is also the number of "vacancies," $V_{t}$. The function is assumed to have constant returns-to-scale. Hence, the rate at which firms fill vacancies is a function of the ratio $\mathcal{N}_{l, t} / u_{t}=\theta_{t}$, a measure of the tightness of the labor market. This vacancy filling rate, $q\left(\theta_{t}\right)$, is given by

$$
q\left(\theta_{t}\right)=\frac{M_{L}\left(\mathcal{N}_{l, t}, u_{t}\right)}{\mathcal{N}_{l, t}} \quad \text { with } q^{\prime}\left(\theta_{t}\right)<0
$$

Conversely, the rate at which the unemployed find a job is

$$
\frac{M_{L}\left(\mathcal{N}_{l, t}, u_{t}\right)}{u_{t}}=\theta_{t} q\left(\theta_{t}\right)=f\left(\theta_{t}\right) \quad \text { with } f^{\prime}\left(\theta_{t}\right)>0 .
$$

Once employed, workers earn a wage $w_{t}$. Two approaches are followed for the wage. First, for simplicity, we assume a wage rule that takes the functional form

$$
w_{t}=\chi_{w}\left(\mathcal{P}_{t} x_{t}\right)^{\eta_{w}}
$$

where $\eta_{w}$ is the elasticity of wages to the marginal product of labor, $\mathcal{P}_{t} x_{t}$. This simple rule, used in Blanchard and Gali (2010), allows us to focus on the role played by the elasticity of wages to productivity for propagation. That is, for a given elasticity of wages, we can evaluate the propagation of shocks to the economy, and in particular the labor market, coming from frictional goods and credit markets.

In the spirit of search models, one may want to have a wage schedule as the outcome of Nash-bargaining between the firm and the worker. This is the second approach in which there is not one, but two wage schedules depending on whether or not the firm is currently selling its production. This will add analytical complications, but makes only a small quantitative difference compared with the simple wage rule. ${ }^{14}$ The wage rule in this case is

$$
w_{t}= \begin{cases}\operatorname{argmax}\left(S_{g, t}-S_{l, t}\right)^{1-\alpha}\left(W_{g, t}-U_{t}\right)^{\alpha} & \text { if the firm is in stage } g \\ \operatorname{argmax}\left(S_{\pi, t}-S_{l, t}\right)^{1-\alpha}\left(W_{\pi, t}-U_{t}\right)^{\alpha} & \text { if the firm is in stage } \pi,\end{cases}
$$

where $W_{g}$ and $W_{\pi}$ are the asset values of employment to a worker, and $U$ is the value of unemployment. The resulting wage rules are

$$
w_{t}= \begin{cases}\alpha \theta_{t}\left(\gamma+\frac{r+s^{c}}{1+r} K\right)-\alpha\left(1+s^{L} \frac{1-s^{c}}{1+r}\right) K+(1-\alpha) b & \text { in stage } g \\ \alpha\left(\mathcal{P}_{t} x_{t}-\Omega-\left[1+s^{L} \frac{1-s^{c}}{1+r}\right] K\right)+\alpha \theta_{t}\left(\gamma+\frac{r+s^{c}}{1+r} K\right)+(1-\alpha) b & \text { in stage } \pi .\end{cases}
$$

The numerical exercise implements the two wage rules and shows that this makes no difference in the results, either qualitatively or quantitatively.

\subsection{Stocks of consumers, employment and unemployment}

Having stipulated the transition rates for all agents in the economy, it is now possible to write the laws of motion for the stocks of consumers, firms and, consequently, employment. Potential consumers, $\mathcal{C}_{0}$, become consumers the period after meeting a producer, and a fraction $0<\tau<1$ of current consumers separate from their product only to return to the pool of potential consumers the following period. The stocks of consumers in the goods market therefore evolve according to stockflow equations, fully reported in Appendix Section 5, which also report the laws of motion for $\mathcal{N}_{g}, \mathcal{N}_{\pi}$, and unemployment.

\footnotetext{
${ }^{14}$ These Bellman equations, along with the derivations of the wage rules, are presented in Appendix Section 4 . A second complication, not fully addressed here, arises from the number of bargaining parties as discussed in Wasmer and Weil (2004). This can lead to several complexities depending on the assumptions on timing and bargaining structure.
} 


\subsection{Equilibrium}

The equilibrium is a set of policy and value functions for the consumers $\left\{D_{0, t}, D_{1, t}, \bar{e}_{c, t}\right\}$ and firms $\left\{S_{c, t}, S_{l, t}, S_{g, t}, S_{\pi, t}\right\}$; a set of prices in goods, labor, and credit; and stocks and measures of tightness in the markets for goods, labor, and credit $\left\{\mathcal{B}_{c, t}, \mathcal{N}_{c, t}, \mathcal{N}_{l, t}, \mathcal{N}_{g, t}, \mathcal{N}_{\pi, t}, \mathcal{C}_{0, t}, \mathcal{C}_{1, t}, u_{t}\right\}$ and $\left\{\xi_{t}, \theta_{t}, \phi\right\}$ such that

1. Consumers' value follows functions (5) and (6), with the search-effort optimality condition (7).

2. The value for firms follows (1)- (4) with free entry in the credit market.

3. Prices in the goods, labor, and credit markets are determined by Nash bargaining given by conditions (9), (18) and (13).

4. Stock in the goods and labor markets follow conditions (10)-(15) of the Appendix.

\section{Calibration strategy}

The basic unit of time is a month. ${ }^{15}$ The process for productivity is assumed to be an AR(1) in logs with persistence of $\rho_{x}=0.90^{1 / 3}$, and conditional volatility, $\sigma_{x}$, to be 0.007 , to match the empirical values in Fujita and Ramey (2007). The matching functions in the labor, goods and credit markets take the functional form proposed in den Haan et al. (2000). All parameter values are reported in Table 2.

Credit market parameters: $r, s^{C}, \beta, \nu_{C}, \kappa_{I}$, and $\kappa_{B}$. The risk-free rate $r$ is set to an annualized $4 \%$. The separation rate $s^{C}$ is set for a $1 \%$ quarterly firm exit rate, as per the evidence reported in Carlstrom and Fuerst (1997). The remaining parameters follow the calibration strategy in Petrosky-Nadeau and Wasmer (2013), to which we refer for details. That is, $K$ is set for a target unemployment rate of $5.80 \%$, the average rate in the U.S. postwar sample. The share of the financial sector in GDP in the model is a strictly increasing function of the bargaining weight $\beta$, and $\beta$ is set to 0.6 to target a $2.5 \%$ share in U.S. data. ${ }^{16}$ The curvature of the credit matching function $\mathcal{N}_{c} \mathcal{B} /\left(\mathcal{N}_{c}^{\nu_{c}}+\mathcal{B}^{\nu_{c}}\right)^{1 / \nu_{C}}$ is set such that the average duration of search in the credit market by creditors is four months, resulting in $\nu_{C}=1$.35. Finally, search flow costs are obtained as $\kappa_{I}=\beta K p(\phi)$ and $\kappa_{B}=(1-\beta) K p \phi(\phi)$.

Labor market parameters: $s^{L}, \nu_{L}, \gamma, \chi_{w}$, and $\eta_{w}$. The five parameters related to the labor market, $s^{L}, \nu_{L}, \gamma, \chi_{w}$, and $\eta_{w}$, are set as follows. The rate of labor separation $s^{L}$ is set such that the aggregate rate of job separation, $s^{C}+\left(1-s^{C}\right) s^{L}$, equals 0.035 per month, consistent with the estimate based on JOLTS data in Davis et al. (2010). Given a value of $s^{c}=0.01 / 3$, we set $s^{L}=\left(0.035-s^{c}\right) /\left(1-s^{c}\right)=0.032$. The curvature parameter in the matching function $\mathcal{N}_{l} \mathcal{U} /\left(\mathcal{N}_{l}^{\nu_{L}}+\mathcal{U}^{\nu_{L}}\right)^{1 / \nu_{L}}$ is set following den Haan et al. (2000) to target an average job filling rate $q(\theta)$ of 0.40 per month. This results in a value $\nu_{L}=1.25$, which is close to the value in the referenced work. The unit vacancy costs are set to $\gamma=0.10$ to be consistent with evidence in Silva and Toledo (2009) that the average cost of recruiting is about $40 \%$ of a monthly wage. Finally, the parameters of the wage rule are set as follows. The level parameter $\chi_{w}$ is set to 0.80 or such that the wage equals 0.75 of labor productivity on average. The elasticity parameter is set to $\eta_{w}=0.75$ such that the elasticity of wages to changes in productivity in the model is about 0.60 , in the upper range of estimates on U.S. aggregate data. ${ }^{17}$

Goods market parameters: $\tau, \nu_{G}, \chi_{\sigma}, \eta_{\sigma}, \delta, \Phi$, and $\Omega$. Broda and Weinstein (2010) report a four-year product exit rate of 0.46 , and a median one year exit rate of 0.24 . These statistics represent the turnover of consumption from the consumer's perspective. In the absence of equivalent data on the turnover of products from the firm's perspective (more empirical work would be welcome here), we need to find a corresponding rate in the model. This is obtained from the model equivalent rate, $s^{c}+\left(1-s^{c}\right)\left[\left(1-s^{L}\right) \tau+s^{L}\right]$, which reflects consumers' transitions from matched to unmatched states, This implies a monthly goods separation rate due to changes in tastes of $\tau=0.005$. Broda and Weinstein (2010) also report a rate of product entry of 0.25 on an annualized basis. This implies an average transition rate for consumers in the goods market of $\tilde{\lambda}=0.20$, targeted with the curvature parameter in the goods market matching function $e_{c} \mathcal{C}_{0} \mathcal{N}_{g} /\left(\left(e_{c} \mathcal{C}_{0}\right)^{\nu_{G}}+\mathcal{N}_{g}^{\nu_{G}}\right)^{1 / \nu_{G}} \cdot{ }^{18}$ This results in $\nu_{G}=1.40$. The search costs in the goods market are calibrated using the Bureau of Labor Statistics' time-use survey. This survey reports that households spend on average half an hour a day purchasing goods and services $(0.4 \mathrm{~h}$ for men, $0.6 \mathrm{~h}$ for women). Of course, this is not necessarily time spent searching and comparing goods before making a choice. Nor does it include travel related to these activities. Assuming an individual works on average seven hours a day, the cost of time searching in the goods market corresponds to approximately $7 \%$ of wage income. That is, the target is an average value for $\sigma(\bar{e}) / w \simeq 0.07$. Assuming a cost function $\sigma(e)=\left(\chi_{\sigma} \backslash \eta_{\sigma}\right) e^{\eta_{\sigma}}$, we obtain $\chi_{\sigma}=0.44$. Our baseline parameterization specifies the costs as quadratic with $\eta_{\sigma}=2$, and then investigates the sensitivity of the results to the degree of curvature later. The share of the goods market surplus accruing to the consumer, $\delta$, is determined by targeting an expenditure share on the essential

\footnotetext{
${ }^{15}$ The models are solved using a projection algorithm as in Petrosky-Nadeau and Zhang (2013a). As a result of the nonlinearity of the model simulation moments are targeted in our calibration rather than steady state relationships. The second moments are computed by taking the averages of the monthly simulated data. The impulse responses of the monthly model are converted to quarters in the same way.

${ }^{16}$ The financial sector's share of GDP in the model is defined $\Sigma_{t}=\left[\left(1-u_{t}\right) \rho_{t}-\gamma \mathcal{N}_{l, t}-\mathcal{B}_{l, t} \kappa_{B}\right] /\left[\mathcal{P}_{t}\left(1-u_{t}\right)+\mathcal{C}_{0, t}\right]$.

${ }^{17}$ Hagedorn and Manovskii (2008), for instance, estimate an elasticity of 0.49 , while Haefke et al. (2013) argue for a value of 0.79 .

${ }^{18}$ At a steady state the annual entry rate of 0.25 implies a monthly consumer finding rate in the goods market of $\tilde{\lambda}=0.25 \mathcal{C}_{1} \tau /\left[\mathcal{C}_{0}\left(1-(1-\tau)^{12}\right)\right]=0.20$ given an average share of matched consumers of $\mathcal{C}_{1}=0.90$ that results from our calibration. It is verified in simulations that the average product exit rate is consistent with the empirical evidence reported above.
} 
Table 2

Baseline monthly parameter values.

\begin{tabular}{|c|c|c|c|c|}
\hline & & Value & & Sources or target \\
\hline \multicolumn{5}{|l|}{ Labor market: } \\
\hline Job-separation rate & $s^{L}$ & 0.032 & $\rightarrow$ & Davis et al. (2010) \\
\hline Matching curvature & $\nu_{L}$ & 1.25 & $\rightarrow$ & den Haan et al. (2000) \\
\hline Vacancy cost & $\gamma$ & 0.10 & $\rightarrow$ & Silva and Toledo (2009) \\
\hline Wage elasticity & $\eta_{w}$ & 0.75 & $\rightarrow$ & Wage elasticity \\
\hline Wage level parameter & $\chi_{w}$ & 0.80 & $\rightarrow$ & Wage to productivity ratio \\
\hline \multicolumn{5}{|l|}{ Goods market: } \\
\hline Goods exit rate & $\tau$ & 0.005 & $\rightarrow$ & Broda and Weinstein (2010) \\
\hline Matching curvature & $\nu_{G}$ & 1.40 & $\rightarrow$ & Goods market transition rate \\
\hline Cost function level parameter & $\chi_{\sigma}$ & 0.44 & $\rightarrow$ & American Time Use Survey \\
\hline Cost function elasticity & $\eta_{\sigma}$ & 2 & $\rightarrow$ & Quadratic cost \\
\hline Consumer bargaining weight & $\delta$ & 0.30 & $\rightarrow$ & Share of expenditure on essential good \\
\hline Marginal utility of $c_{1}$ & $\Phi$ & 1.15 & $\rightarrow$ & Price markup \\
\hline Production cost & $\Omega$ & 0 & & \\
\hline \multicolumn{5}{|l|}{ Credit market: } \\
\hline Separation rate & $s^{c}$ & $0.01 / 3$ & $\rightarrow$ & Bernanke et al. (1996) \\
\hline Bank bargaining weight & $\beta$ & 0.62 & $\rightarrow$ & Petrosky-Nadeau and Wasmer (2013) \\
\hline Search costs & $\kappa_{B}=\kappa_{I}$ & 0.1 & $\rightarrow$ & Petrosky-Nadeau and Wasmer (2013) \\
\hline Risk-free rate & $r$ & $0.01 / 3$ & $\rightarrow$ & 3 month U.S. T-bill \\
\hline \multicolumn{5}{|l|}{ Technology } \\
\hline Persistence parameter & $\rho_{x}$ & $0.90^{1 / 3}$ & $\rightarrow$ & BLS labor productivity \\
\hline Standard deviation & $\sigma_{x}$ & 0.007 & $\rightarrow$ & BLS labor productivity \\
\hline
\end{tabular}

good in the data. Data from the Household Consumption Expenditure Survey reveal that the average annual expenditure on food consumed at home, plus utilities, over the period 1984-2009 amounts to 10-15\% of total annual expenditures. The share in the model is defined as $\mathcal{C}_{0} /\left[\mathcal{P C}_{1}+\mathcal{C}_{0}\right]$, where the expenditures are weighted by the fraction of unmatched and matched consumers. This results in $\delta=0.30$. The marginal utility $\Phi$ is set to 1.15 for an average markup over marginal cost of $10 \%$, in the lower range of values reported in Basu and Fernald (1997) and Nekarda and Ramey (2011). ${ }^{19}$ The cost of production parameter is assumed negligible and set to $\Omega=0$, avoiding any amplification that could arise from the introduction of an additional fixed element in the profit flow during the sales stage.

\section{Quantitative results}

\subsection{The sources of propagation}

Fluctuations in the labor market are driven by the decision of firms to create jobs. Thus, a job-creation condition, an equation relating labor market tightness to the expected value of a hired worker, lies at the heart of propagation. Combining Eqs. (1) and (2), and calling $o_{t} \equiv\left(\left(1-q_{t}\right)\left(r+s^{c}\right)\right) / q_{t}(1+r)$, a quantitatively negligible term, this job-creation condition is ${ }^{20}$

$$
\underbrace{K\left(\phi^{*}\right)\left(1+o_{t}\right)}_{\text {Cost of credit frictions }} \underbrace{+\frac{\gamma}{q\left(\theta_{t}\right)}}_{\text {Cost of labor frictions }} \underbrace{=\frac{1-s^{c}}{1+r} \mathbb{E}_{t} S_{g, t+1}}_{\text {Expected profits }}
$$

which equates the average cost of creating a job - the left-hand side, equal to the financial costs properly discounted, $K$, and the expected costs of search on the labor market, $\gamma / q\left(\theta_{t}\right)$ - to the discounted expected value of a worker to the firm in the goods market stage (the right-hand side).

A few words of comparison with the canonical labor search model are warranted here. First, the costs of financial intermediation enter the left-hand side of the equation and place a lower bound on the value of a "vacancy" to a firm. Absent credit market frictions, the average cost of creation depends on the flow cost of a vacancy, $\gamma$, and congestion in the labor market. Second, the expected value on the right-hand side corresponds to the ability to produce and sell a good once a consumer has been located. Under frictionless goods markets, the right-hand side is simply the value of the profit stage. Thus, the current model nests the canonical search model when $K$ tends to zero and the goods market friction is removed.

The relationship between labor market tightness and the expected value of a filled vacancy to a firm becomes very transparent when looking at a log-linear approximation of this job-creation condition around the deterministic steady

\footnotetext{
${ }^{19}$ This mark up is defined in the model as $\mathcal{P}_{t} \mathcal{N}_{\pi, t} /\left[\mathcal{N}_{g, t} w_{t}+\mathcal{N}_{\pi, t}\left(w_{t}+\Omega\right)\right]$.

${ }^{20}$ With our calibration values $o_{t}$ is approximately equal to 0.01 .
} 
state:

$$
\underbrace{\hat{\theta}_{t}}_{\text {Amplification from : Labor frictions Credit frictions Goods frictions }}=\underbrace{\frac{1}{\eta_{L}}} \times \underbrace{\hat{\mathbb{E}}_{S_{g}, t+1}}_{S_{g}-K}
$$

where $\eta_{L}$ is the elasticity of the job-filling rate with respect to labor market tightness and "hatted" variables indicate proportional deviations from the steady state. Over and above the amplification of changes in $S_{g}$ from frictions in the labor market, measured as the inverse of the elasticity of the labor-matching function, credit market frictions create an amplifying factor of $S_{g} /\left(S_{g}-K\right)$. This financial accelerator is decreasing in the firm's surplus to hiring a worker, $S_{g}-K$. Note that frictions in the goods market will also affect the value of $S_{g}$ and provide amplification through the known channel of reducing the firm's surplus, $S_{g}-K$. However the amplification from the goods market in the second term in the right-hand side $S_{g} /\left(S_{g}-K\right)$ only occurs when $K>0$. A similar decomposition of the elastiticies and derived multipliers can be found in Sargent and Ljungqvist (2014).

The main additional and novel effects of goods market frictions on the dynamics of the labor market work through their impact on the dynamics of the expected value of a filled vacancy, $\mathbb{E}_{t} \widehat{S}_{g, t+1}$.

Consider the value of a filled vacancy in a standard Mortensen-Pissarides matching model where the goods market is perfect:

$$
S_{g, t}^{M P}=x_{t}-w_{t}+\left(\frac{1-s^{L}}{1+r}\right) \mathbb{E}_{t} S_{g, t+1}^{M P} .
$$

From the recursive nature of $S_{g, t}^{M P}$, all that matters for the dynamics of labor market tightness under perfect goods markets is the expected path of the net profit flow, $x_{t}-w_{t}$. Two features of the goods market fundamentally change the dynamics: (i) the likelihood of reaching the profit stage in the period after hiring the worker, $\lambda_{t}$, which will affect the value of $\mathbb{E}_{t} \widehat{S}_{g, t+1}$, and (ii) the expected profit flow, which depends on the price of the goods, $\mathcal{P}_{t}$.

\subsection{Advertising as an additional source of amplification from goods market frictions}

The benchmark model introduced endogenous consumer search effort, which was procyclical, and consistent with the search behavior exhibited in the introduction. This section introduces, by symmetry, the case of simultaneous consumer search effort and advertising effort. ${ }^{21}$

The model with advertising effort $e_{A, t}$ and no consumer search is symmetrical to the model with consumer effort. The transitions in the goods market are now: $\tilde{\lambda}_{t}=M_{G}\left(\mathcal{C}_{0, t}, \bar{e}_{A, t} \mathcal{N}_{g, t}\right) / \mathcal{C}_{0, t}$ and $\lambda_{t}=M_{G}\left(\mathcal{C}_{0, t}, \bar{e}_{A, t} \mathcal{N}_{g, t}\right) / \mathcal{N}_{g, t}$, and the cost of advertising effort is specified as $\sigma_{A, t}=\left(\chi_{A} / \eta_{A}\right) e_{A, t}^{\eta_{A}}$ with $\chi_{A}>0$ and $\eta_{A}=2$. The level parameter $\chi_{A}=1.5$ to target a ratio of advertising costs to GDP of $2 \%$, as documented in Tremblay and Tremblay (2012).

The first order condition for advertisement effort is

$$
\sigma_{A}^{\prime}\left(e_{A, t}\right)=\frac{\lambda_{t}}{\bar{e}_{A, t}}\left(1-s^{L}\right)\left(\frac{1-s^{c}}{1+r}\right) \mathbb{E}_{t}\left[S_{\pi, t+1}-S_{g, t+1}\right]
$$

The search efforts of both sides of the goods market are procyclical as they follow the marginal expected surplus from the goods market match. This procyclicality of advertising is empirically confirmed by Hall (2012) for the U.S. Finally, the resulting price equation is

$$
\mathcal{P}_{t} x_{t}=(1-\delta)\left[v\left(x_{t}\right)\right]+\delta\left[\Omega-\left(1-\eta_{A}\right) \sigma_{A}\left(e_{A, t}\right)\right]
$$

It is possible to allow for endogenous search effort on both sides of the goods market. In this case, combining the optimality conditions for the intensive search margins (8) and (21), yields

$$
\frac{\bar{e}_{A, t} \sigma_{A}^{\prime}\left(e_{A, t}\right)}{\bar{e}_{c, t} \sigma_{c}^{\prime}\left(e_{c, t}\right)}=\left(\frac{1-\delta}{\delta}\right)\left(1-s^{L}\right)\left(1-s^{c}\right) \xi_{t}
$$

Since effort of one side increases the returns to effort of the other side, there is a strategic complementarity arising from bilateral search effort. This can potentially increase the amplification of productivity shocks relative to the baseline model of

\footnotetext{
${ }^{21}$ As rightly pointed out by a referee, there is a total of six intensive search margins in the model. Four additional search margins could have been introduced: in the credit market, search effort of creditors and new investment projects; and in the labor market, recruiting effort by firms and search effort by the unemployed. It can be shown that three out of the four intensive margins are actually invariant to the cycle due to free entry assumptions. The invariance of firm recruiting effort, for instance, was already shown in Pissarides (2000, chapter 5). Only the last one, search effort by the unemployed, generates procyclical search behavior, arising from the convexity in the costs of job search for workers and the procyclicality of the returns to search effort. Recent empirical research is uncovering evidence of pro-cyclical effort by firms in the goods market (Hall, 2012) and the labor market. Indeed, with regards to the latter, work by Davis et al. (2013) suggests some interesting cyclical properties of firm recruiting intensity in the labor market. Such patterns of cyclical recruiting intensity in the micro data could be modeled by incorporating adjustment costs to vacancy creation. This is likely to increase amplification of productivity shocks and has received extensive attention in the literature (Pissarides, 2009). However, such a mechanism is not going to raise persistence. This is why our model focuses on the intensive search margins in the goods market, detailed in this section, which will be shown to raise persistence. The main equations are provided here and the details of the derivations are presented in Appendix Section 7.
} 


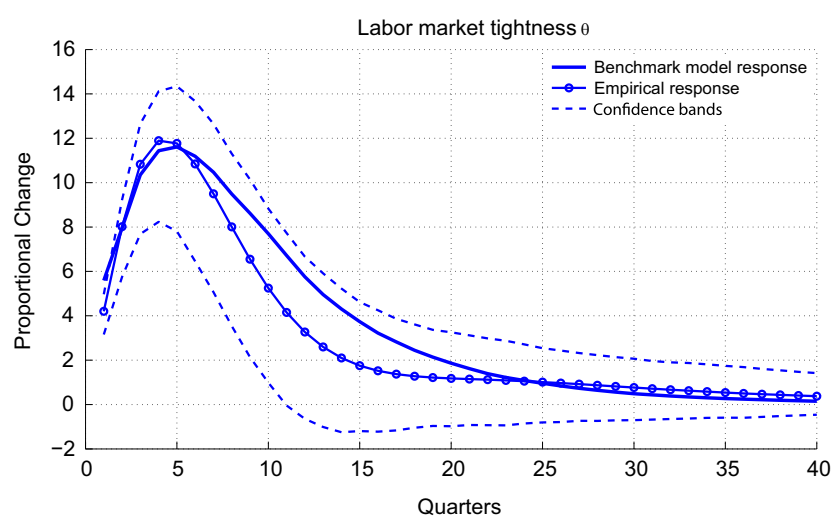

Fig. 1. Empirical and benchmark model labor market tightness impulse response to a positive technology shock. Note: Labor market tightness is the ratio of vacancies to unemployment. Data (empirical response) from Fujita and Ramey (2007).

Section 2, but is not required to generate persistence in the effects of the shocks. It may even reduce it as the two endogenous intensive search margins can adjust very fast. The extensive search margins are slower to adjust as they depend on the evolution of state variables driven by stock-flow equations. This will be the case in the quantitative results.

\subsection{The response of labor market tightness to technology shocks: amplification and persistence}

The dynamics of the model's impulse response to productivity innovations are described first in order to illustrate the various determinants of amplification and persistence. In particular, emphasis is place on the fit with our main empirical target, the impulse response of labor market tightness to an identified productivity shock in U.S. data by Fujita and Ramey (2007). The second moments of labor market variables in the model and in the data are discussed next. The baseline responses and second moments between alternative specifications of the model are then compared, with a particular focus on the role of frictions in each market. These alternative economies are calibrated to match the same average unemployment rate as the benchmark model. Finally, a sensitivity analysis to goods market parameters is performed.

Fig. 1 plots the impulse response of labor market tightness, in the model and the data, to a 1\% technology shock. As emphasized by Fujita and Ramey (2007), the empirical response of labor market tightness (circled line) peaks five quarters after the innovation. This feature of the data is absent in the standard labor search model. ${ }^{22}$ The benchmark model's response (solid line) follows the empirical response closely. The initial response, close to a $6 \%$ deviation, is well below the peak response of $12 \%$ after five quarters. The model response is well within the empirical $90 \%$ confidence interval (dashed lines).

The first panel (top left) of Fig. 2 plots the evolution of labor market tightness, while the second panel (top right) reports the impulse response of the expected values of a filled vacancy, $\mathbb{E}_{t} S_{g, t+1}$. The expected value of a filled vacancy peaks five periods after the realization of the shock, generating an inverted U-shape for the response of labor market tightness. Fig. 2 also reports the response of the goods market meeting rate for firms, $\lambda$ (third panel) and price, $\mathcal{P}$ (fourth panel) that enter the job creation condition (19), along with consumer search effort (fifth panel) and goods market tightness (sixth panel) in order to shed light on the dynamics introduced by goods market frictions. These are the key aspects of the goods market that create the intertemporal linkages between the labor and goods markets, and are the novel features of our model with respect to the literature. Firms expect a drop in the next period's consumption tightness and the likelihood of finding a consumer for their goods after the realization of the technology shock. This arises from an inflow of new goods on the market greater than the change in effective consumer demand, or equivalently from a drop in the tightness of the goods market, $\xi=\mathcal{C}_{0} / \mathcal{N}_{\mathrm{g}}$. However, this is partially undone by the rise in consumer search effort. Indeed, as shown in Eq. (8), an increase in the expected surplus value of the consumption match, due to the rise in the consumer goods-meeting rate, $\tilde{\lambda}$, and a decline in the price $\mathcal{P}$, will raise consumers' search effort to get a share of this surplus.

The rise in effort by consumers and decline in goods market tightness have a second effect. They lead to a drop in the negotiated price $\mathcal{P}$. This effect acts to limit the incentives to create jobs in the immediate period following the technology shock. In the subsequent periods, consumers increase their search effort in the goods market further in response to the drop in prices and the rise in their disposable income. This improves the position of firms in price negotiations such that the price $\mathcal{P}$ is increasing even as technology is returning to trend. The evolution of the goods market thus generates increasing incentives to hire workers even as technology is returning to trend, allowing labor market tightness to increase for several quarters after the innovation.

\footnotetext{
${ }^{22}$ Shi's (1998) approach of search in the goods market is able to replicate the hump-shaped pattern of the data, although in his case it is in response to a shock to the growth rate of money supply.
} 

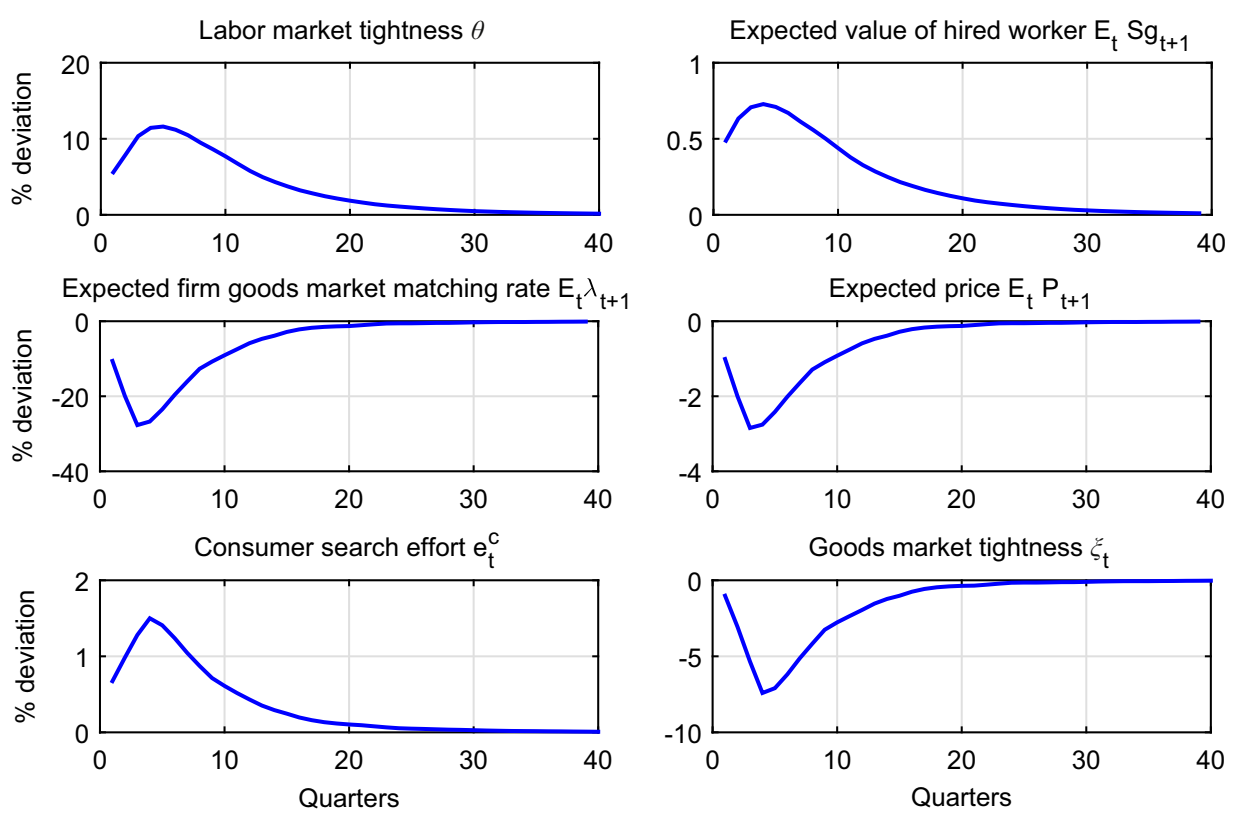

Fig. 2. Goods market frictions, inspecting the propagation mechanism: impulse responses to a $1 \%$ positive technology shock in the benchmark model.

Table 3

Labor market second moments, benchmark model and model variants.

\begin{tabular}{|c|c|c|c|c|c|c|c|c|}
\hline & \multicolumn{3}{|c|}{ Standard deviation } & \multicolumn{2}{|c|}{ Autocorr. $\Delta \theta_{t}$} & \multicolumn{2}{|c|}{ Autocorr. $\Delta V_{t}$} & \multirow[t]{2}{*}{$\operatorname{Corr}(U, V)$} \\
\hline & $\theta$ & $U$ & $V$ & Lag 1 & Lag 2 & Lag 1 & Lag 2 & \\
\hline U.S. data & 0.27 & 0.13 & 0.14 & 0.68 & 0.36 & 0.68 & 0.39 & -0.91 \\
\hline \multicolumn{9}{|l|}{ Benchmark model credit-labor-goods (CLG) frictions } \\
\hline Cyclical consumer effort only & 0.24 & 0.10 & 0.15 & 0.30 & 0.06 & 0.06 & -0.01 & -0.79 \\
\hline \multicolumn{9}{|l|}{ Variants on intensive search margins, CLG model } \\
\hline Variant 1 . Two sided effort (consumer and firm) & 0.24 & 0.09 & 0.16 & 0.27 & 0.04 & 0.09 & -0.01 & -0.79 \\
\hline Variant 2. Firm effort only (advertising for goods) & 0.28 & 0.11 & 0.17 & 0.22 & 0.01 & 0.06 & -0.04 & -0.79 \\
\hline Variant 3. Fixed consumer effort and advertising effort & 0.21 & 0.07 & 0.13 & 0.26 & 0.04 & 0.05 & -0.01 & -0.78 \\
\hline \multicolumn{9}{|l|}{ Variants on extensive search margins in other markets } \\
\hline Variant 4. Labor frictions only (L) & 0.03 & 0.01 & 0.02 & 0.13 & -0.09 & -0.14 & -0.10 & -0.77 \\
\hline Variant 5. Credit-labor frictions only (CL) & 0.17 & 0.08 & 0.10 & 0.13 & -0.08 & -0.14 & -0.10 & -0.72 \\
\hline Variant 6. Goods-labor frictions only (GL) & 0.15 & 0.06 & 0.09 & 0.29 & 0.02 & 0.07 & -0.02 & -0.85 \\
\hline
\end{tabular}

Notes: BLS and Petrosky-Nadeau and Zhang (2013b). The data for the first row are the seasonally adjusted monthly unemployment (rate, persons 16 years of age and older) from the Bureau of Labor Statistics. The seasonally adjusted measure of job vacancies, $V$, is from Petrosky-Nadeau and Zhang (2013b). The series is monthly from January 1951 to December 2012. Both $U$ and $V$ are converted to quarterly averages of monthly series, and $\theta=V / U$. For the moments in the first three and the final columns, all variables are in HP-filtered proportional deviations from the mean with a smoothing parameter of 1600 . The middle columns report the autocorrelation at the first and second lags after first differencing the log of the variable. In the following rows we simulate 5000 artificial samples from the respective models, with 744 monthly observations in each sample. We take the quarterly averages of monthly $U, V$, and convert to quarterly observations. We implement the exactly same empirical procedures as on these quarterly series, and report the cross-simulation averages of standard deviation and autocorrelations of growth rate for all the models.

\subsection{Second moments and the respective roles of the different market frictions}

This section explores the propagation properties of frictions in the goods market through several model variants, and contrast them with the canonical labor search model and a model with credit market imperfections. The first three columns of Table 3 report the standard deviations of HP filtered data and model labor market tightness $\theta$, unemployment $u$, and job vacancies $V=\mathcal{N}_{l}$. The next four columns report the first- and second-order autocorrelation of the growth rate of labor market tightness $\theta$ and vacancies $V$. The final column reports the correlation between unemployment and vacancies.

The first row of Table 3 reports the moments from U.S. quarterly data over the period 1951:I to 2012:IV. Labor market variables display large fluctuations over the business cycle in the data, a well-known fact, and are very persistent at the first 
and second lags. This persistence in the data has received less attention. The subsequent rows present the results for the benchmark model and six different variants described below.

\subsubsection{The benchmark model}

The benchmark model with frictional goods, labor and credit markets, and consumer effort generates standard deviation of labor market tightness, unemployment, and vacancies of $0.24,0.10$, and 0.15 , respectively. While our main empirical target for persistence is the empirical impulse response to an identified technology shock, it can be informative to compare the autocorrelations in model variables. The model generates some persistence on labor market tightness, especially as compared to alternative models with no goods market imperfections (variants 4 and 5 in particular, as discussed below). Indeed, there is a positive first- and second-order correlation in labor market tightness with consumer effort. The model also delivers positive first-order correlation in vacancies which, as discussed below, is not the case when goods market frictions are absent. However, the model is still far away from the data on this dimension, and additional ingredients may be needed to match it more closely, such as additional job creation costs or convex vacancy costs.

\subsubsection{Variants with different intensive search margins (variants 1-3)}

Variant 1 introduces advertisement costs which interact complementarily with consumer effort, as explained above. This adds to the volatility of vacancies, but it mildly reduces the persistence of labor market tightness, while improving that of vacancies. The benchmark model is preferred nonetheless since it matches labor market tightness volatility and persistence better. Variant 2 has instead no consumer effort and only advertising effort. ${ }^{23}$ There is more volatility and less persistence in labor market tightness than in the benchmark model. Quite interestingly, shutting down both endogenous search margins, as in variant 4 with a constant consumer effort, does not eliminate amplification and persistence. Both remain quite high, and larger than in the alternative models without goods market frictions discussed below.

\subsubsection{Variants with no frictions on goods or credit markets (variants 4-6)}

Variants 4-6 present variants to the benchmark credit-labor-goods (CLG) model. Variant 4 is a model with a frictional labor market but perfect credit and goods markets (model L). Variant 5 is a model with frictional credit and labor markets and perfect goods market (model CL) and variant 6 is a model with labor and goods market frictions and perfect credit markets (model GL). ${ }^{24}$

Removing the friction in the credit and goods market reduces volatility. Removing both credit and goods market frictions (Variant 4) brings the standard deviation of unemployment down to 0.01 and the standard deviation of labor market tightness to 0.03 . Starting from Variant 4 and adding credit market imperfections (Variant 5) adds a factor of 5-6 to the volatility. The standard deviation of labor market tightness reaches 0.17 (as in Petrosky-Nadeau and Wasmer, 2013). Starting from Variant 4 and adding goods market imperfections only (Variant 6) adds a factor of 4-5 to the volatility. The standard deviation of labor market tightness reaches 0.15 . As shown in the benchmark model and its variants $1-3$, the combination of both goods and credit market friction generates an even larger degree of amplification. Hence frictions in credit and goods markets are similar and complementary in generating amplification.

Fig. 3 compares the responses of labor market tightness $\theta_{t}$ to a productivity shock in these four comparison models. The benchmark CLG model generates amplification and persistence that is very apparent in the hump-shaped pattern of the response as discussed earlier. The GL model loses some amplification but, significantly, retains some persistence in the response. The hump-shaped pattern is clear, although slightly less pronounced. The CL model's response is similar in magnitude to the GL model yet loses all the persistence. The peak response is contemporaneous to the innovation. The $\mathrm{L}$ model fails in terms of both amplification and persistence. This again emphasizes the unique feature of frictions in the goods market, namely the ability to generate endogenous persistence in labor market variables.

The column on the autocorrelation of both $\Delta \theta_{t}$ and $\Delta V_{t}$ confirms this conclusion, showing the uniqueness of goods market frictions in generating persistence compared with credit market frictions. Both the labor and credit-labor models display first-order autocorrelations of labor market tightness growth of about a third of that in the benchmark model. In regards to the persistence in vacancies, only the presence of goods market frictions leads to a positive first-order autocorrelation. However, as argued above, additional features would be needed to better match the data. Summarizing, goods market frictions contribute most to improving the qualitative and quantitative dynamics of labor market variables.

\subsection{Sensitivity to goods market parameters and wage setting}

This section discusses the sensitivity of the main results to changes in goods market parameter values. In particular, it presents results with different values of (i) $\eta_{\sigma}$, the elasticitity of the consumer search cost function; (ii) $\nu_{G}$, the curvature of the goods market matching function, and; (iii) $\tau$, the frequency of consumer taste shocks.

\footnotetext{
${ }^{23}$ In this variant the level parameter $\chi_{A}$ is set to 1.5 .

${ }^{24}$ These alternative economies are calibrated to match the same average unemployment rate as the benchmark model by adjusting the flow cost of vacancies $\gamma$ in the GL and L models, and by adjusting $\gamma$ and the credit market costs $K$ in proportion in the CL model.
} 


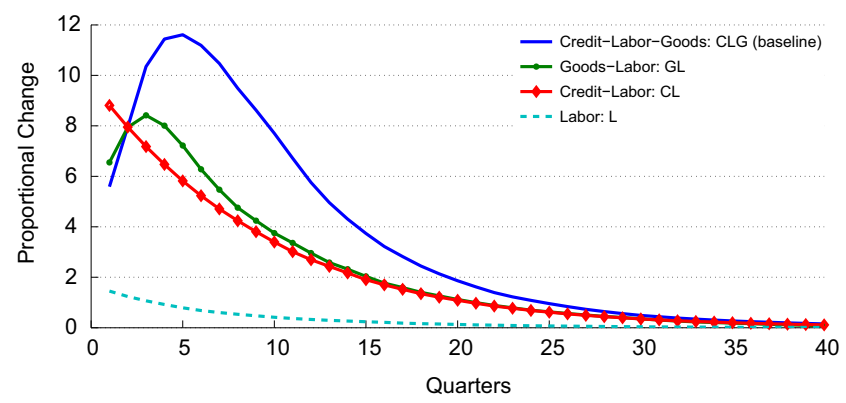

Fig. 3. Comparing frictions: impulse responses to a positive technology shock across the benchmark credit-labor-goods frictions and variants goods-labor, credit-labor, and labor market frictions alone.

Table 4

Labor market second moment: sensitivity analysis.

\begin{tabular}{|c|c|c|c|c|c|c|c|c|}
\hline & \multicolumn{3}{|c|}{ Standard deviation } & \multicolumn{2}{|c|}{ Autocorr. $\Delta \theta_{t}$} & \multicolumn{2}{|c|}{ Autocorr. $\Delta V_{t}$} & \multirow[t]{2}{*}{$\operatorname{Corr}(U, V)$} \\
\hline & $\theta$ & $U$ & $V$ & Lag 1 & Lag 2 & Lag 1 & Lag 2 & \\
\hline U.S. data & 0.27 & 0.13 & 0.14 & 0.68 & 0.36 & 0.68 & 0.39 & -0.91 \\
\hline Baseline (CLG, $\eta_{\sigma}=2, \nu_{G}=1.5$ ) & 0.24 & 0.10 & 0.15 & 0.30 & 0.06 & 0.06 & -0.01 & -0.79 \\
\hline \multicolumn{9}{|l|}{ Alternative search cost elasticity } \\
\hline$\eta_{\sigma}=1.90$ & 0.22 & 0.08 & 0.15 & 0.27 & 0.02 & 0.07 & -0.02 & -0.83 \\
\hline$\eta_{\sigma}=2.10$ & 0.26 & 0.12 & 0.15 & 0.31 & 0.11 & 0.010 & 0.02 & -0.77 \\
\hline \multicolumn{9}{|l|}{ Alternative matching curvature } \\
\hline$\nu_{G}=1.1$ & 0.23 & 0.09 & 0.15 & 0.29 & 0.04 & 0.07 & -0.01 & -0.82 \\
\hline$\nu_{G}=1.9$ & 0.26 & 0.11 & 0.15 & 0.30 & 0.07 & 0.03 & 0.00 & -0.77 \\
\hline \multicolumn{9}{|c|}{ Alternative frequency of taste shocks } \\
\hline$\tau=0.0075$ & 0.25 & 0.11 & 0.15 & 0.30 & 0.07 & 0.04 & 0 & -0.78 \\
\hline$\tau=0.0025$ & 0.22 & 0.09 & 0.15 & 0.30 & 0.05 & 0.08 & -0.01 & -0.81 \\
\hline Baseline (CLG) and Nash wage & 0.23 & 0.10 & 0.16 & 0.29 & 0.03 & 0.05 & -0.01 & -0.80 \\
\hline
\end{tabular}

Notes: We simulate 5000 artificial samples from the respective models, with 744 monthly observations in each sample. We take the quarterly averages of monthly $U, V$, and convert to quarterly observations. For the moments in the first three and the final columns, all variables are in HP-filtered proportional deviations from the mean with a smoothing parameter of 1600. The middle columns report the autocorrelation at the first and second lags after first differencing the log of the variable.

Table 4 reproduces the main moments and compares them with alternative values of the curvature to the search cost function $\sigma(e)$. In particular, instead of a quadratic cost function, with $\eta_{\sigma}=2$, smaller values of the elasticity (1.75) have a marginal effect on volatility and persistence, while a larger elasticity (2.25) only marginally reduces the volatility (standard deviation of labor market tightness) and slightly raises the autocorrelation of first differences (the persistence). The intuition for the higher volatility comes from inspection of Eq. (8). The larger $\eta_{\sigma}$, the steeper the marginal cost in the left-hand side. The level of effort thus reacts less to changes in the right-hand side, which captures the surplus from the consumption relation. Overall, the model and our conclusions are quite stable with respect to values of $\eta_{\sigma}$ around 2 .

Alternative values of the goods market matching function curvature parameter leave the main moments almost unchanged. Amplification and persistence outcomes are preserved in a range for $\nu_{G}$ of 1.1-1.9.

The impact of changing the frequency of taste shocks in the goods market, $\tau$, by $50 \%$ on the main results is examined next. Recall that such a shock sends the product back to the goods market search stage but does not result in the destruction of the product. Reducing $\tau$ from 0.005 to 0.0025 or increasing it to 0.0075 does not change the benchmark conclusions.

Finally, since the rigidity of wages to changes in labor productivity play an important role in amplifying technology shocks in labor market search models (see Hall, 2005; Shimer, 2005), it is important to explore alternative wage determination scenarios. We compare the business cycle statistics of the baseline model CLG solved with the Nashbargained wages defined in Eq. (18). ${ }^{25}$ Nash-bargained wages do not change the results with respect to either volatility or

\footnotetext{
${ }^{25}$ In parameterizing the CLG model with Nash wages, $b$ is set to 0.71 as in Hall and Milgrom (2008) and the bargaining weight $\alpha$ is set to 0.15 to target a wage elasticity of 0.70 .
} 
persistence. The business cycle second moments in Table 4 indicate that the degree of amplification is comparable to the baseline model.

\section{Relation to the literature}

Early research into propagation in business cycle models focused on the labor market, either increasing the elasticity of labor supply - e.g., models of indivisible labor in Hansen (1985) and Rogerson (1988) - or introducing a market friction in the form of wage rigidity (e.g., Taylor, 1980; Christiano et al., 2005). The importance of the latter in amplifying the response of the demand for labor to changes in productivity has received renewed attention in search models of equilibrium unemployment as a means of addressing the lack of volatility in job vacancies and unemployment. In this sense, our work is related, first, to that of Shimer (2005), which fully articulates the lack of amplification in the search model of equilibrium unemployment. Second, it is related to the work of Fujita and Ramey (2007) who document the persistence in the empirical response of labor market tightness to a productivity shock, and propose treating vacancies as a stock variable to generate sluggishness in the response to shocks.

The role of credit markets in amplifying exogenous shocks to economies and the existence of a financial accelerator has been emphasized in such papers as Bernanke and Gertler (1989) and Kiyotaki and Moore (1997). We take into account the potential importance of frictional credit markets by introducing a financial accelerator of the type explored in Wasmer and Weil (2004) and Petrosky-Nadeau and Wasmer (2013). These papers considered the static and dynamic properties of the financial accelerator that arises from the interaction of frictional labor and credit markets.

Our main novelty here is to develop a model in which the introduction of goods market imperfections generates additional insights into the sources of macroeconomic dynamics when allowed to interact with a frictional labor market. It has, of course, long been recognized that non-clearing or departures from Walrasian equilibria in goods markets can generate additional unemployment. Several waves of research have attempted to put this intuition into models (see the survey in Benassy, 1993). This previous literature has mostly been centered around the idea of price rigidities leading to excess supply of (or demand for) goods, which in turn generate inefficient outcomes in the labor market. In our paper, expected profits, and hence labor demand, depend on the ability of the supply and demand in the goods market to meet, and flexible prices contribute even further to the propagation mechanism. In this we are continuing a tradition of the search literature with an explicit focus on frictions in the goods market (e.g., Diamond, 1971, 1982), and more recently in the conclusions drawn in Diamond (2011): "For addressing unemployment, there are clear needs to incorporate credit markets and (non-Walrasian) output markets and to include nominal thinking and nominal contracting as well as a larger role for current income."

Goods markets are indeed characterized by the presence of rents and product turnover that lend themselves to be modeled as search-and-matching markets. The earliest paper related to ours is Shi (1998). As noted above, his approach of search in the goods market is able to generate the hump- shaped pattern of the data, which is another confirmation of the importance of search in the goods market. His model is more in the tradition of monetary economics. It incorporates money demand and the velocity of money, and the economy reacts to shocks to the growth rate of money. In addition, contrary to our model, the seller's surplus is countercyclical.

Price mark ups over marginal cost are prevalent in goods markets and remain a core feature of New Keynesian models of the macroeconomy. A certain degree of market power permits firms to charge mark ups in the range of $11-40 \%$, according to Basu and Fernald (1997) and Nekarda and Ramey (2011), respectively. ${ }^{26}$ Price mark ups can also indicate the presence of frictions in locating consumers. They are indicative of having to establish and maintain a distribution network. Retail trade, for instance, amounts to 5.8\% of aggregate GDP in the U.S., suggesting a costly allocation of final goods to consumers operated by intermediaries. Moreover, Foster et al. (2008) present evidence for frictions in accessing a distribution network or reaching consumers. New firms face lower demand than comparable older firms, and they are willing to charge a lower price. Note that this same evidence also suggests the presence of costs for consumers to acquire information about a producer. These frictions lead to time and costs for both sides of the goods market in searching before acquiring or beginning to consume a good for the first time.

Over and above these observations, new data on household goods transactions paint a portrait of the goods market akin to the flows of gross and net creation and destruction in the labor and credit markets. Following Davis and Haltiwanger's (1990, 1992) seminal contributions for labor markets, Dell'Ariccia and Garibaldi (2005) have measured creation and destruction in the U.S. loans market, while, most recently, Broda and Weinstein (2010) have carefully documented the magnitude of flows of entry and exit of goods in a typical household's consumption basket. ${ }^{27}$ Relevant to our approach, they find large flows of entries and exits of "products" in a typical consumer's consumption basket, actually four times more than is found in labor markets. Over their nine year sample period, 1994-2003, the product entry rate, defined as the number of new product codes divided by the stock, is estimated to be $78 \%$. The product exit rate, defined as the number of disappearing product codes over the stock, is $72 \%$. These empirical findings suggest that a good theory should follow, as in our paper, the

\footnotetext{
${ }^{26}$ Similar estimates of mark ups are found in Bils (1987) and Rotemberg and Woodford (1999).

27 The authors built and used a unique data set of 700,000 products with bar codes purchased by 55,000 households. The covered sectors amount to $40 \%$ of all expenditures on goods in the CPI.
} 
birth of a "product line," its development, and finally its death due in part to technological obsolescence, in part to changes in consumer tastes.

Last but certainly not least, the closest paper to ours is Bai et al. (2011). The authors independently developed a model with a process of matching between consumers and firms in the goods market in a DSGE framework. They use the same convincing argument that buying goods is an active process involving costs, which should, therefore, be part of a macroeconomic model. Their focus is on the impact of demand shocks in goods markets, and in particular their implications for the identification of technology shocks within the RBC paradigm. In contrast, ours is on the propagation of productivity shocks to the cyclical dynamics of the labor market. In their model, a competitive search environment with price posting, differentiated markets are indexed by the price and market tightness. As a result, across markets, prices are higher when goods are easier to find. Our model introduces search effort and price bargaining: search effort increases when future expected surplus is higher, which has implications in terms of the fit with the data. These ingredients turn out to be necessary to replicate the observed persistence in U.S. time series. Another independent work by Gourio and Rudanko (2014) focuses on frictions in the goods market with a focus on "customer acquisition" as a search friction in the goods market. Their paper investigates the level and volatility of firm level variables such as investment and sales and calculates a Tobin's q. An earlier paper in this literature is Lehmann and Van der Linden (2010) which introduced search frictions in both product and labor markets. Finally, den Haan (2013) provides a detailed theory of inventory in line with search frictions in the goods market, a dimension that we ignored here but that deserves more development.

\section{Conclusion}

This paper investigates the significance of goods market frictions for the dynamics of the labor market. The model with search frictions in the goods market features an amplified and persistent response to productivity shocks. This arises from new features of the dynamics of prices, goods market congestions, and from consumer search effort absent from models with perfect goods markets. Goods market frictions lead to rich intertemporal linkages between the labor and goods markets. The dynamics of goods market congestion and prices limit the initial response of labor market tightness to a producitivity shock, while increasing the incentives to hire in the ensuing quarters. This unique aspect of goods market frictions is robust to introducing endogenous search effort on both sides of the market, consumers and firms.

Our model of a frictional economy is a natural framework for introducing additional sources of shocks, in particular demand shocks and money as in Bai et al. (2011) and Berentsen et al. (2011), or financial shocks as in Jermann and Quadrini (2012). We note in closing that despite recent empirical findings on the intensive margins on both sides of the market advertising effort as in Hall (2012) and consumer search effort as in Petrosky-Nadeau et al.'s (2014) work on shopping time little is known about the extensive margins and the nature of the matching process in the goods market. This is in stark opposition to the extensive work measuring matching frictions and turnover costs in the labor market. There is a clear need for deeper empirical research into the nature of turnover and the matching function in the goods market. In particular, a better understanding of the behavior of inventories (e.g., den Haan, 2013) and of the attachment of customers to goods (e.g., Gourio and Rudanko, 2014) is needed.

\section{Acknowledgments}

We thank the editor, an anonymous referee, Evi Pappa, Peter Rupert, Espen Moen, Johannes Schmieder, Thijs Van Rens, Guido Menzio, Randall Wright, Philipp Kircher, Shigeru Fujita and the seminar participants at the LAEF Micro-Macro Labor Models, CEPR/ECB Labor Markets conferences, University of Amsterdam, Norwegian School of Management, CREI, UC-Irvine, University of Southern California, Penn Search and Matching Workshop, Federal Reserve Banks of Richmond and San Francisco, and the Kiel Institute New Developments, and Thema-Cergy Macro-Labor conferences for helpful comments. We also thank Garey Ramey and Shigeru Fujita for kindly sharing their data with us. This work was in part undertaken during the two authors' stay at UCSB-LAEF, the hospitality of which is gratefully acknowledged. We finally thank the editor Urban Jermann and an anonymous referee. Financial support from ANR-11-LABX-0091 (LIEPP), ANR-11-IDEX-0005-02 and ANR 2010 BLANC 181901 (EvalPolPub) is also acknowledged. The views expressed here are those of the authors alone and not of the Federal Reserve System.

\section{Appendix A. Supplementary data}

Supplementary data associated with this article can be found in the online version at http://dx.doi.org/10.1016/j.jmoneco. 2015.01.006. 


\section{References}

Altig, D., Christiano, L., Eichenbaum, M., Linde, J., 2011. Firm-specific capital, nominal rigidities and the business cycle. Rev. Econ. Dyn. 14 (2), $225-$ 247. Andolfatto, D., 1996. Business cycles and labor-market search. Am. Econ. Rev. 86 (1), 112-132.

Bai, Y., Rios-Rull, V., Storesletten, K., 2011. Demand Shocks That Look Like Productivity Shocks. Mimeo, University of Minnesota. Basu, S., Fernald, J.G., 1997. Returns to scale in U.S. production: estimates and implications. J. Polit. Econ. 105 (2), 249-283. Benassy, J.-P., 1993. Nonclearing markets: microeconomic concepts and macroeconomic applications. J. Econ. Lit. 31 (2), $732-761$. Berentsen, A., Menzio, G., Wright, R., 2011. Inflation and unemployment in the long run. Am. Econ. Rev. 101 (1), 371-398. Bernanke, B., Gertler, M., 1989. Agency costs, net worth, and business fluctuations. Am. Econ. Rev. 79 (1), 14-31. Bernanke, B., Gertler, M., Gilchrist, S., 1996. The Financial Accelerator and the Flight to Quality. Rev. Econ. Stat. 78 (1), 1-15. Bils, M., 1987. The cyclical behavior of marginal cost and price. Am. Econ. Rev. 77 (5), 838-855.

Blanchard, O., Galí, J., 2010. Labor markets and monetary policy: a new Keynesian model with unemployment. Am. Econ. J.: Macroecon. 2 (2), 1-30. Broda, C., Weinstein, D.E., 2010. Product creation and destruction: evidence and price implications. Am. Econ. Rev. 100 (3), $691-723$.

Carlstrom, C.T., Fuerst, T.S., 1997. Agency costs, net worth, and business fluctuations: a computable general equilibrium analysis. Am. Econ. Rev. 87 (5), 893-910.

Christiano, L.J., Eichenbaum, M., Evans, C.L., 2005. Nominal rigidities and the dynamic effects of a shock to monetary policy. J. Polit. Econ. 113 (1), 1 45. Christiano, L.J., Motto, R., Rostagno, M., 2014. Risk shocks. Am. Econ. Rev. 104 (1), 27-65.

Cogley, T., Nason, J.M., 1995. Effects of the Hodrick-Prescott filter on trend and difference stationary time series implications for business cycle resehıణ

Davis, S.J., Faberman, R.J., Haltiwanger, J.C., 2013. The establishment-level behavior of vacancies and hiring. Q. J. Econ. 128 (2), 581-622.

Davis, Steven J., Faberman, R. Jason, Haltiwanger, John C., Rucker, Ian., 2010. Adjusted estimates of worker flows and job openings in JOLTS. In: Abraham, K. G., Spletzer, J.R., Harper, M.J. (Eds.), Labor in the New Economy, University of Chicago Press, Chicago, pp. 187-216.

Davis, S.J., Haltiwanger, J., 1990. Gross job creation and destruction: Microeconomic evidence and macroeconomic implications. In: NBER

MacAmeroorotape, vol. 5, NBER Chapters. National Bureau of Economic Research, Inc., pp. 123-186.

Davis, S.J., Haltiwanger, J.C., 1992. Gross job creation, gross job destruction, and employment reallocation. Q. J. Econ. 107 (3), 819-863.

Dell'Ariccia, G., Garibaldi, P., 2005. Gross credit flows. Rev. Econ. Stud. 72 (3), 665-685.

den Haan, W., 2013. Inventories and the Role of Goods-Market Frictions for Business Cycles. Mimeo, London School of Economics.

den Haan, W.J., Ramey, G., Watson, J., 2000. Job destruction and propagation of shocks. Am. Econ. Rev. 90 (3), 482-498.

Diamond, P.A., 1971. A model of price adjustment. J. Econ. Theory 3 (2), 156-168.

Diamond, P.A., 1982. Aggregate demand management in search equilibrium. J. Polit. Econ. 90 (5), 881-894.

Diamond, P.A., 2011. 2010 Nobel Prize in Economics Lecture. The Nobel Foundation.

Duffie, D., Gârleanu, N., Pedersen, L.H., 2005. Over-the-counter markets. Econometrica 73 (6), 1815-1847.

Foster, L., Haltiwanger, J., Syverson, C., 2008. Reallocation, firm turnover, and efficiency: selection on productivity or profitability?. Am. Econ. Rev. 98 (1), 394-425.

Fujita, S., Ramey, G., 2007. Job matching and propagation. J. Econ. Dyn. Control 31 (11), 3671-3698.

Gertler, M., Kiyotaki, N., 2013. Banking, Liquidity and Bank Runs in an Infinite-Horizon Economy. Working Paper 19129, National Bureau of EcorRessiarch.

Gourio, F., Rudanko, L., 2014. Customer capital. Rev. Econ. Stud. 81 (3), 1102-1136.

Haefke, C., Sonntag, M., van Rens, T., 2013. Wage rigidity and job creation. J. Monet. Econ. 60 (8), 887-899.

Hagedorn, M., Manovskii, I., 2008. The cyclical behavior of equilibrium unemployment and vacancies revisited. Am. Econ. Rev. 98 (4), $1692-1706$.

Hall, R.E., 2005. Employment fluctuations with equilibrium wage stickiness. Am. Econ. Rev. 95 (1), 50-65.

Hall, R.E., 2012. The Cyclical Response of Advertising Refutes Counter-Cyclical Profit Margins in Favor of Product-Market Frictions. NBER Working Papelis370, National Bureau of Economic Research, Inc.

Hall, R.E., Milgrom, P.R., 2008. The limited influence of unemployment on the wage bargain. Am. Econ. Rev. 98 (4), 1653-1674.

Hansen, G.D., 1985. Indivisible labor and the business cycle. J. Monet. Econ. 16 (3), 309-327.

Jermann, U., Quadrini, V., 2012. Macroeconomic effects of financial shocks. Am. Econ. Rev. 102 (1), 238-271.

King, R.G., Rebelo, S.T., 1999. Resuscitating real business cycles. In: Taylor, J.B., Woodford, M. (Eds.), Handbook of Macroeconomics, vol. 1. Elsepier927-1007. (Chapter 14).

Kiyotaki, N., Moore, J., 1997. Credit cycles. J. Polit. Econ. 105 (2), 211-248.

Lehmann, E., Van der Linden, B., 2010. Search frictions on product and labor markets: money in the matching function. Macroecon. Dyn. 14 (1), $56-92$. Merz, M., 1995. Search in the labor market and the real business cycle. J. Monet. Econ. 36 (2), 269-300.

Michaillat, P., Saez, E., 2014. An Economical Business-Cycle Model. NBER Working Papers 19777, National Bureau of Economic Research, Inc. Mortensen, D.T., Pissarides, C.A., 1999. New developments in models of search in the labor market. In: Ashenfelter, O., Card, D. (Eds.), Handbook of Labor

Economics, vol. 3. Elsevier, pp. 2567-2627. (Chapter 39).

Negro, M.D., Eggertsson, G., Ferrero, A., Kiyotaki, N., 2011. The Great Escape? A Quantitative Evaluation of the Fed's Liquidity Facilities. Staff Reports 520 Federal Reserve Bank of New York.

Nekarda, C.J., Ramey, V.A., 2011. Industry evidence on the effects of government spending. Am. Econ. J.: Macroecon. 3 (1), 36-59.

Petrosky-Nadeau, N., Wasmer, E., 2013. The cyclical volatility of labor markets under frictional financial markets. Am. Econ. J.: Macroecon. 5 (1), $193-221$. Petrosky-Nadeau, N., Wasmer, E., Zeng, S., 2014. Shopping Time. Working Paper 2014-24, FRB San Francisco.

Petrosky-Nadeau, N., Zhang, L., 2013. Solving the DMP Model Accurately. Working Paper 19208, National Bureau of Economic Research.

Petrosky-Nadeau, N., Zhang, L., 2013. Unemployment Crises. Working Paper 19207, National Bureau of Economic Research.

Pissarides, C.A., 2000. Equilibrium Unemployment Theory. The MIT Press, Boston.

Pissarides, C.A., 2009. The unemployment volatility puzzle: is wage stickiness the answer?. Econometrica 77 (5), 1339-1369.

Rogerson, R., 1988. Indivisible labor, lotteries and equilibrium. J. Monet. Econ. 21 (1), 3-16.

Rogerson, R., Shimer, R., 2011. Search in macroeconomic models of the labor market. In: Handbook of Labor Economics, vol. 4. Elsevier, p. 61 (Chapter 7). Rotemberg, J.J., Woodford, M., 1999. The cyclical behavior of prices and costs. In: Taylor, J.B., Woodford, M. (Eds.), Handbook of Macroeconomics, vol. Hlsevier, pp. 1051-1135. (Chapter 16).

Sargent, T., Ljungqvist, L., 2014. The Fundamental Surplus in Matching Models. Mimeo, New York University.

Shi, S., 1998. Search for a monetary propagation mechanism. J. Econ. Theory 81 (2), 314-352.

Shi, S., 2011. Customer Relationship and Sales. Working Papers tecipa-429, University of Toronto, Department of Economics.

Shimer, R., 2005. The cyclical behavior of equilibrium unemployment and vacancies. Am. Econ. Rev. 95 (1), 25-49.

Silva, J.I., Toledo, M., 2009. Labor turnover costs and the cyclical behavior of vacancies and unemployment. Macroecon. Dyn. $13,76-96$.

Taylor, J.B., 1980. Aggregate dynamics and staggered contracts. J. Polit. Econ. 88 (1), 1-23.

Tremblay, Victor J., Tremblay, Carol H., 2012. New Perspectives on Industrial Organization With Contributions from Behavioral Economics and Game Theospringer.

Wasmer, E., 2009. A Steady-State Model of a Non-Walrasian Economy With Three Imperfect Markets. Discussion Paper 2011-5758,

IZA. Wasmer, E., Weil, P., 2004. The macroeconomics of labor and credit market imperfections. Am. Econ. Rev. 94 (4), 944-963. 